\title{
Collaborative Approaches to Team-Based Primary Health Care for Individuals with Dementia in Rural/Remote Settings*
}

\author{
Amanda Froehlich Chow, Debra Morgan, Melanie Bayly, Julie Kosteniuk, and Valerie Elliot \\ Canadian Centre for Health and Safety in Agriculture, University of Saskatchewan
}

\begin{abstract}
RÉSUMÉ
L'application d'approches d'équipes en soins de santé de première ligne (SPL) pour le diagnostic et le traitement de la démence est considérée comme une pratique exemplaire. Malheureusement, il arrive fréquemment que les personnes vivant dans les régions rurales et éloignées aient peu d'accès à des services de SPL spécialisés pour la démence. Le but de cet examen de la portée était d'identifier et de comprendre les approches d'équipes en SPL pour les soins en milieu rural visant les cas de démence. La stratégie de recherche utilisée a uniquement inclus des articles de revues à comité de lecture publiés entre 1997 et 2017. Quatre bases de données (Embase, Medline PsycInfo et CINAHL) ont été consultées de mars 2017 à mai 2017. Les dix études retenues montraient des degrés de collaboration et des interactions variables dans les équipes de soins. Peu d'informations étaient rapportées sur les stratégies de collaboration de ces équipes. Une adaptation du modèle socioécologique a été utilisée pour catégoriser les facteurs clés influençant les approches collaboratives. Ces résultats rassemblés pourraient être utilisés pour guider la recherche future et l'élaboration d'un modèle de soins de santé de première ligne pour la démence dans les milieux ruraux.
\end{abstract}

\begin{abstract}
Applying primary health care (PHC) team-based approaches to diagnosing and treating dementia is considered best practice. Unfortunately, those living in rural and remote areas often have limited access to dementia-specific PHC services. The purpose of this scoping review was to identify and understand PHC team-based approaches for dementia care in rural settings. A search strategy was employed which included only peer-reviewed journal articles that were published from 1997 to 2017. Four databases (Embase, Medline, PsycInfo, and CINAHL) were searched from March 2017 to May 2017. Among the 10 studies included there was a variation in the degree of collaboration and interaction among the care teams. Limited information existed about collaboration strategies among care teams. An adaptation of the socio-ecological model enabled us to categorize key factors influencing collaborative team-based approaches. Combined, these findings can be used to inform both future research and the development of a rural PHC dementia model.
\end{abstract}

* Funding for this research was provided by the Saskatchewan Health Research Foundation through a partnership with the Canadian Institutes of Health Research, in support of the Canadian Consortium in Neurodegeneration in Aging (CCNA) (grant number 3431). Additional support was provided by the College of Medicine, University of Saskatchewan, as postdoctoral funding for Amanda Froehlich Chow.

Manuscript received: / manuscrit reçu : 09/05/18

Manuscript accepted: / manuscrit accepté : 25/09/18

Mots-clés : vieillissement, démence, soins de santé de première ligne, soins interdisciplinaires/interprofessionnels, rural et éloigné, personnes âgées

Keywords: aging, dementia, primary health care, interdisciplinary/interprofessional care, rural and remote, older adults La correspondance et les demandes de tirés-à-part doivent être adressées à : / Correspondence and requests for offprints should be sent to:

Amanda Froehlich Chow, Ph.D.

Canadian Centre for Health and Safety in Agriculture

104 Clinic Place

P.O. Box 23

University of Saskatchewan

Saskatoon SK S7N 2Z4

(a.fc@usask.ca)

Canadian Journal on Aging / La Revue canadienne du vieillissement 38 (3) : 367-383 (2019)

Copyright (C) Canadian Association on Gerontology 2019. This is an Open Access article, distributed under the terms of the

Creative Commons Attribution licence (http://creativecommons.org/licenses/by/4.0/), which permits unrestricted re-use,

distribution, and reproduction in any medium, provided the original work is properly cited. 


\section{Background}

Dementia is a disease that affects the lives of millions of older adults (65 years and older) both in Canada and across the globe (Prince, Comas-Herrera, Knapp, Guerchet, \& Karagiannidou, 2016). Dementia is a clinical syndrome of deterioration in cognition that negatively affects daily functioning, and it is not an outcome of delirium or another condition (i.e., medical, neurological, or psychiatric) (Chertkow, Feldman, Jacova, \& Massoud, 2013). The most common causes of dementia include Alzheimer's disease (50-75\%), followed by vascular dementia (20-30\%), frontotemporal dementia $(5-10 \%)$, and dementia with Lewy bodies $(<5 \%)$ (Prince, Albanese, Guerchet, \& Prina, 2014). As a result of the aging population, it is expected that the number of Canadians living with dementia will reach 937,000 by 2031 (Alzheimer Society of Canada, 2016). Further, diagnosing dementia can be a complex and complicated process, and due to the high rates of undiagnosed cases, this is likely an underestimate of true prevalence (Bradford, Kunik, Schulz, Williams, \& Singh, 2009).

In Canada and beyond, underdiagnoses and misdiagnosis of dementia pose a significant barrier to effective dementia treatment and management (Prince et al., 2016). At the same time, there is a large body of research that emphasizes the importance of early diagnosis and treatment in improving the quality of life and health outcomes among those living with dementia (Barth, Nickel, \& Kolominsky-Rabas, 2018; Morgan et al., 2015; Prince et al., 2016). Applying a team-based care approach to managing chronic conditions, including dementia, has been recommended as efficient, cost-effective, and patient-centred (Chamberlain-Salaun, Mills, \& Usher, 2013; Morgan et al., 2015). Ideally, with adequate training and support, a primary health care (PHC) team can effectively diagnose and manage dementia among their patients (Massoud, Lysy, \& Bergman, 2010).

In Canada, PHC refers to primary prevention, public health, and health care services supplied by a range of providers in a variety of settings, in a way that is person- and population-centred (Canadian Institutes of Health Research, 2014). Collaborative PHC teams are typically led by a family physician and consist of health care professionals from varying disciplines (Reeves et al., 2015); this type of approach is often referred to as interprofessional team-based care. Another term to describe this type of collaboration is interdisciplinary. Both interprofessional and interdisciplinary indicate coordinated collaboration among health care professionals from different disciplines. Common elements associated with interprofessional/ interdisciplinary team-based care include (a) shared team identity with clear individual roles; (b) collaborative work towards common goals and objectives; (c) strong understanding of other team members' knowledge, roles, and expertise; (d) shared responsibility and team decision-making processes; and (e) open communication and information-sharing procedures (Mickan \& Rodger, 2005; Reeves et al., 2011, 2015). The type and number of professionals that make up the team may vary largely depending on the availability of services in the area. In the literature, interprofessional and interdisciplinary are often used interchangeably with multiprofessional or multidisciplinary, and these terms all refer to multiple health care professionals caring for the same patient; however, coordinated and ongoing collaboration is lacking among multiprofessional/multidisciplinary disciplines (Chamberlain-Salaun et al., 2013).

In an effort to better understand the factors influencing interprofessional teamwork, Reeves et al. (2015) developed a theoretical framework consisting of four domains influencing team-based collaboration: relational, processual, organizational, and contextual. Dahlke et al. (2017) recently applied this framework in their scoping review aimed at understanding how interprofessional teams are able to improve health outcomes of older adults experiencing cognitive challenges. Results of this study indicated that (a) collaboration among staff, (b) communication mechanisms, and (c) education interventions were most effective in supporting interprofessional collaborations that resulted in positive outcomes for care teams and patients. Their research highlighted the value of applying a team-based approach when caring for older adults with cognitive challenges. However, the authors also identified the need for further research aimed at describing the processes that teams use to collaborate. Moreover, as indicated in the framework created by Reeves et al. (2011), it is also important to understand how broader contextual and environmental factors (e.g., geographic locale, availability of health care professionals, policies, and access to resources) may impact the processes employed by teams.

For instance, geographic setting (i.e., rural versus urban) can have a significant impact on the availability of health care professionals and resources which, in turn, impacts the ability of a PHC team to work collaboratively (Dandy \& Bollman, 2008; Ford, 2016; Morgan et al., 2015). In Canada, adults aged 65 years and older account for approximately 20 per cent of the rural population, compared to approximately 16 per cent of the urban population (Statistics Canada, 2016). In addition, evidence suggests there is a higher incidence and prevalence of dementia in rural areas (Russ, Batty, Hearnshaw, Fenton, \& Starr, 2012). In the literature, a variety of definitions are applied to define and describe rurality. Given the variation in rural environments, researchers have advised against applying one single definition to describe rural; rather, it is suggested that authors provide a detailed description of how the term 
rural is operationalized within their study (Keating, Swindle, \& Fletcher, 2011; Moazzami, 2015). Generally, there are common features identified among all rural and remote settings: unique social patterns, a widely dispersed population, an economy that is often agriculturally based, and with limited access to health care resources including dementia-specific primary health care services (Morgan et al., 2015; Prince et al., 2016). Such information is necessary for understanding the implications and generalizability of study findings to other rural settings outside of the target population. Limited access to health care resources is particularly concerning when considering the role of PHC teams in dementia care (Prince et al., 2016). Moreover, research reveals numerous challenges associated with access to dementia care in rural areas (Morgan et al., 2015), with little information about evidence-based best practices to guide team-based care for rural residents living with dementia (Innes, Morgan, \& Kostineuk, 2011; Morgan et al., 2015).

Collaborative team-based PHC has been identified as a best-practice approach to delivering dementia care (Aminzadeh, Molnar, Dalziel, \& Ayotte, 2012; Morgan et al., 2015). However, limited information exists about how PHC teams collaborate to deliver dementia care specifically to individuals living in rural areas with limited resources. Consequently, the aim of our study was to conduct a scoping review of the literature to determine how PHC teams collaborate to deliver comprehensive and integrated dementia care to older adults residing in rural and remote areas. In addition, this study was part of a larger research project in collaboration with the Canadian Consortium on Neurodegeneration in Aging (CCNA). The CCNA, which includes a Women, Gender, Sex and Dementia cross-cutting program (WGSD), is working to increase knowledge and understanding about the underlying genetic, physiological, and social differences between females and males and how these sex and gender differences contribute to the pathology of dementia and delivery of care for persons with dementia (Tierney, Curtis, Chertkow, \& Rylett, 2017). Accordingly, a secondary objective of this scoping review was to examine sex and gender differences in relation to needs and care approaches for patients and families, and, in turn, to examine how PHC teams function to deliver care for rural and remote residents living with dementia.

\section{Methods}

The overall review process followed Arksey and O'Malley's (2005) scoping review framework, with additional guidance from Levac, Colquhuon, and O'Brien (2010). The guiding framework includes the following five stages: (a) identifying the research aim and question; (b) identifying the relevant research studies; (c) study selection; (d) charting the data; and (e) collating, summarizing, and reporting the results.

\section{Identifying the Research Questions}

As suggested by Levac et al. (2010), we gave careful consideration to the population of interest, concepts, and health-related outcomes. Health care professionals caring for rural residents living with dementia and persons with dementia living in rural areas were identified as the target population. The primary outcome of interest was to understand how PHC teams engage in collaborative approaches to deliver dementia care to rural residents. Our secondary goal for this scoping review was to examine sex and gender differences in relation to needs and care approaches for patients and families and, subsequently, to learn how PHC teams function to deliver care for rural and remote residents living with dementia. In an effort to gain detailed information about the processes involved in team-based collaboration, the research team (AFC, DM, MB, JD, VE) identified two specific research questions:

(1) Do primary health care teams describe the team type (e.g., interprofessional, multiprofessional, interdisciplinary), and if so, what are the team compositions?

(2) What are the factors (facilitators and barriers) that have been identified as influencing the implementation of collaborative team-based primary health care approaches for dementia in rural and remote areas?

\section{Identifying Relevant Studies}

The comprehensive search strategy we pursued was devised and reviewed by the University of Saskatchewan's Health Sciences librarian. The strategy focused on four main topics: team type, dementia, primary health care, and rural/remote location. The search was conducted in four electronic databases (Embase, Medline, PsycINFO, and CINAHL). We searched the databases from March 1, 2017, to May 1, 2017. The search was limited to empirical research studies published in peerreviewed journals; we excluded letters to the editor, opinion letters, commentaries, dissertations, reviews, policy papers, reports, grey literature, and book chapters. To be included, studies had to focus on team-based primary health care delivered by providers from multiple disciplines. Additionally, papers were considered eligible if they presented data on diagnosis and treatment of dementia (all types) and if at least 80 per cent of the participants were aged 65 years and older. Further, articles needed to include study participants who resided in rural and remote areas; however, studies which encompassed participants from urban settings were included if rural-urban comparisons were made. Given the wide variation in definitions applied to describe rural, we accepted studies containing any description of rural. Upon an initial database search, we identified no relevant studies prior to the past 20 years; thus, the search included studies published between 
1997 and 2017. An example of our search strategy, including keywords used, can be found in Table 1 .

\section{Study Selection}

The search resulted in 189 studies which we uploaded to software (EndNote). Once duplicates were identified (via EndNote) and removed, 166 studies remained and were included in title and abstract screening. The included articles were then exported to an electronic systematic review program (DistillerSR). Two reviewers (AFC, MB) independently reviewed the titles and abstracts of all articles. The full texts from all potentially eligible studies were then reviewed by these same two reviewers using a screening form developed by the first author (AFC). All studies (10) which met the inclusion criteria during the full-text review were included in the scoping study (Figure 1). During the entire review process, a third reviewer was identified to act as an adjudicator (DM) in the event that the first two reviewers could not come to agreement; however, this issue did not arise.

\section{Charting the Data}

The first author developed a customized data charting table in Excel which we used to guide data extraction. Developing the data charting table was an iterative process; consequently, the table was revised on the basis of feedback from research team members to ensure that key data were captured. The final table contained information pertaining to study characteristics that included author, title, and year; study purpose; methods, participants (age and proportion of males versus females), and settings (including identifying those residing in rural and/or remote areas); and findings relevant to the aim of the scoping review (Table 2 ).

\section{Collating, Summarizing, and Reporting}

We collated the data to determine study locations (countries), geographic settings (rural/remote and urban), and the types of studies included. As a team, we engaged in several meetings to discuss how we could use the extracted data to address the scoping review's goals of understanding how primary health care teams collaborate to deliver comprehensive and integrated dementia care to older adults residing in rural and remote areas. We analysed data to assess how PHC teams defined themselves and determine team compositions. In addition, we reported factors (facilitators and barriers) that were identified as key elements influencing collaboration among PHC teams working to diagnose and care for rural and remote residents living with dementia.

Table 1: Search terms

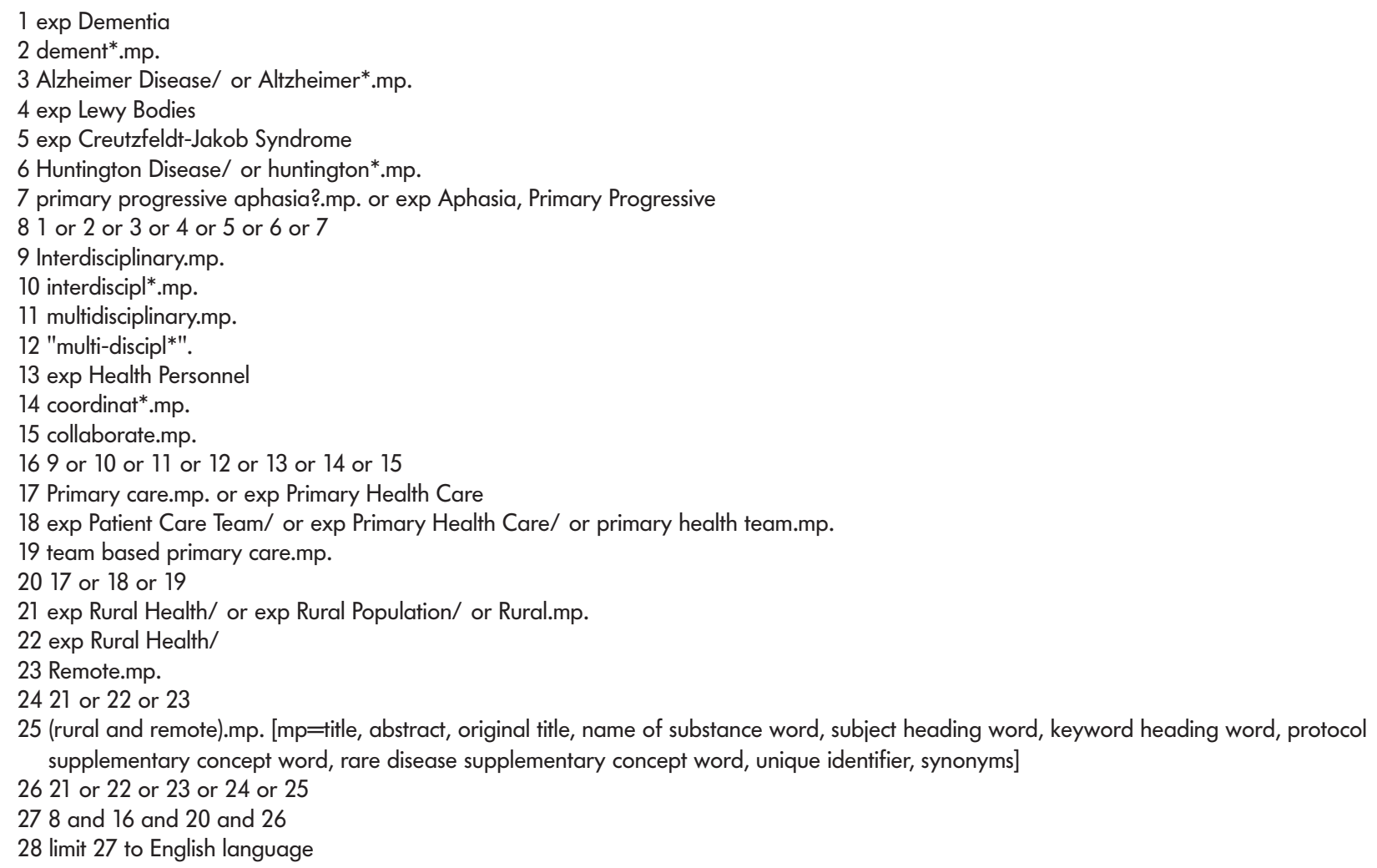




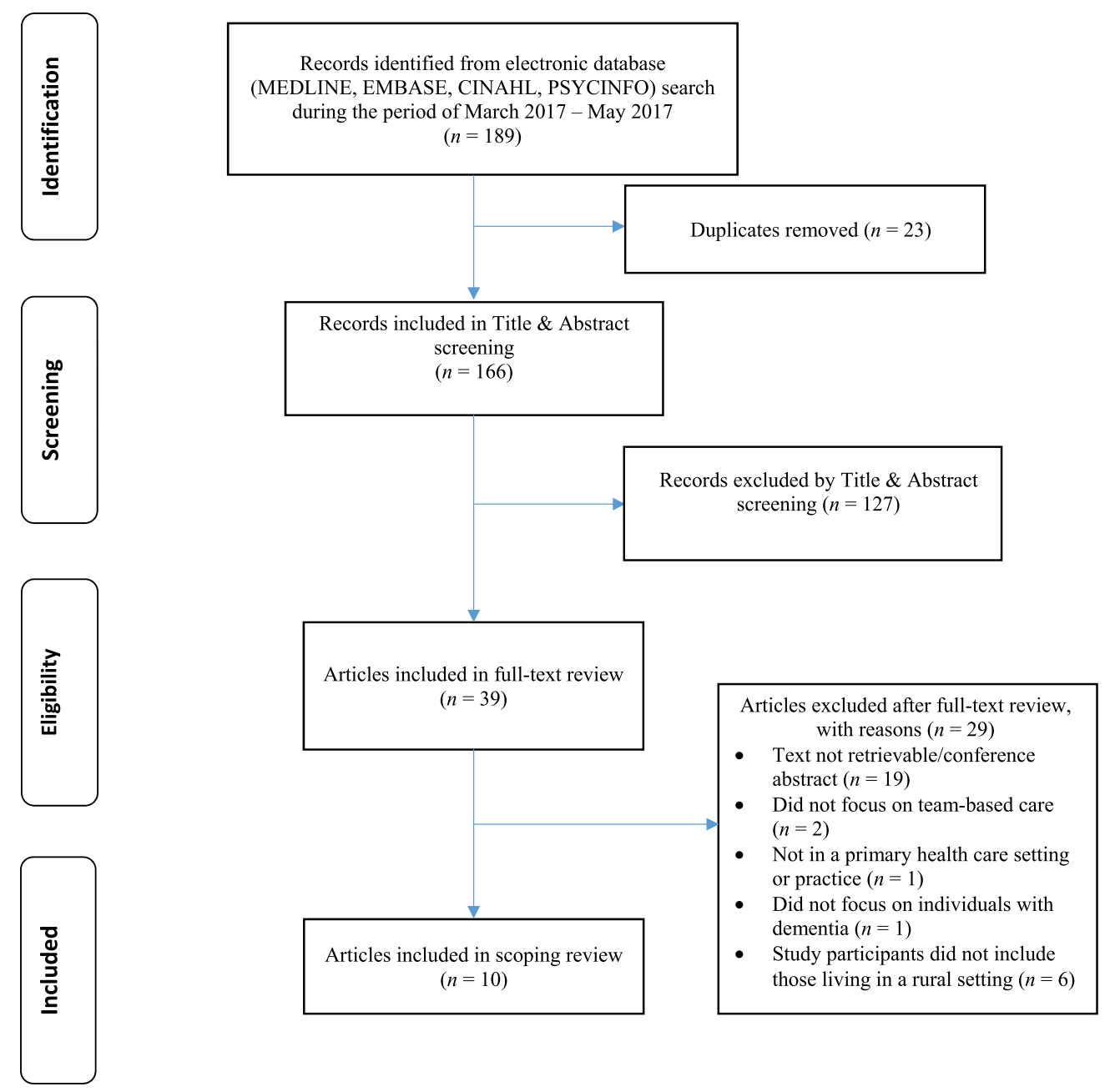

Figure 1: PRISMA flow chart

An adapted version of the socio-ecological model (Figure 2) was the framework we employed to report factors identified as influencing team-based collaborations (McLeroy, Bibeau, Steckler, \& Glanz, 1988; Misfeldt, Suter, Oelke, \& Hepp, 2017; Mulvale, Danner, \& Pasic, 2008). This framework highlights specific factors that influence behaviours on the assumption that ecological categories are systematically connected. Applying the socio-ecological model has most commonly been used to identify and understand how interrelated factors at multiple levels affect health-related behaviours. Few studies have employed this model when exploring how PHC teams collaborate, particularly in relation to the delivery of dementia care in rural settings. We employed an adapted version of the socio-ecological model which had been applied in previous research aimed at understanding key factors that influence the interactions among interprofessional PHC teams (Misfeldt et al., 2017; Mulvale et al., 2008).

At the centre of the adapted version of the socioecological model are primary care teams (i.e., team level), which employ a collaborative team-based approach to delivering primary health care. Examples of factors at the team level include (a) team dynamics, (b) division of roles within teams, (c) team leadership, (d) communication strategies, and (e) interaction with patients (Goldman, Meuser, Rogers, Lawrie, \& Reeves, 2010; Misfeldt et al., 2017; Mulvale et al., 2008). The second level (organizational) focuses on factors such as team culture, team vision and goal, training and education, and interactions with health professionals outside of the primary care team (Misfeldt et al., 2017; Goldman et al., 2010). Lastly, the outermost level (systems) considers factors within the broader context such as socioeconomic and political influences. This would include resource availability (human and financial), space, infrastructure, and existing polices. We used the adapted socio-ecological model in our study to guide the reporting of key themes identified in relation to team-based approaches for diagnosing and treating dementia among rural and remote residents. 


\begin{tabular}{ll}
\hline Author, Year, \& Title & \multicolumn{1}{c}{ Purpose } \\
\hline Lliffe et al. (2014) & $\begin{array}{c}\text { To adapt a US model of } \\
\text { primary care-based case }\end{array}$ \\
Introducing case management & management for people \\
for people with dementia & with dementia and test \\
in primary care: A mixed- & it in general practice \\
methods study & clinics in England
\end{tabular}

Obstacles to shared care

for patients with dementia:

A qualitative study

To identify specialist and generalist physicians' perceptions of the potential for shared
Methods, Participants, \& Setting

Relevant Findings

Methods: Mixed-methods case studies were employed to assess the adaption and implementation of a care-based case managemen model in rural and urban primary care clinics.

Sample/Participants: Patients included individuals with dementia living at home $(n=28)$ and family caregivers $(n=29)$.

Setting: The model was implemented in four primary care practices ( 2 inner cities, 1 rural, 1 suburban).

Methods: Semi-structured tape-recorded interviews were carried out with participants. care approaches when caring for those with dementia
Participants \& Setting: Geriatric specialists $(n=29)$ and generalist physicians $(n=30)$. Specialists and general practitioners (GPs) were located in clinics from both rural and urban locations. the model. members.

\section{Powers et al. (2017)}

Creation of an interprofessiona

eledementia clinic for rura

veterans: Preliminary data
To determine the feasibility and patient satisfaction

for an interprofessional teledementia clinic using clinical video telehealth (CVT) to deliver care to rural veterans
Methods: Metrics were gathered (number of rural patients served, savings in travel time distance, and costs) to evaluate the effectiveness of a CVT model in providing dementia assessment and follow-up care for rural veterans.

Participants \& Setting: All participants were male with the average age of 77.8 years. Between initial and follow up appointments $75 \%$ of patients resided in rural Pennsylvania (some patients transitioned to an urban area following the initial appointment). Interprofessional care teams were located in an urban setting (Pittsburg, Pennsylvania, USA).

Rojas-Fernandez et al. (2014) An interdisciplinary memory clinic: A novel practice setting for pharmacists in primary care
To understand and describe the role of clinical pharmacists in providing care to patients with dementia symptoms in a primary care interdisciplinary memory clinic
Methods: Mixed methods were employed to evaluate how clinical pharmacists effectively collaborate with a primary care interdisciplinary team.

Participants \& Setting: Individuals with dementia $(n=30,000)$ from both rural and urban areas. Interdisciplinary team located in an urban centre (Kitchener, Ontario, Canada).
- Flexibility was built into the case management role, which could be tailored to each discipline (nurse or social worker), practice, and individual. This increased care team's fidelity to adopting

- Patients valued the one-to-one care given by the team

- Challenges identified included lack of time for implementation and onerous research documentation procedures.

- Four broad themes emerged: (1) Therapeutic nihilism - specialists felt that GPs lacked the skill and commitment to undertake dementia diagnosis and management; (2) Risk reduction/avoidance - the risks of early diagnoses are managed with interdisciplinary approaches to care and family/caregiver support; (3) Competencies - GPs believed that the clinical care of dementia should be a specialist task and did feel confident in their abilities to diagnose and create treatment plans for patients; (4) Resources \& Roles - GPs and specialists felt they could work together with other health professionals if time and additional staff were in place.

- Development and standardization of tools (interview templates, visit documentation, and discharge documentation) was indicated as essential to implementing the CVT model.

- Regular bi-weekly meetings among interprofessional teams were key to the team's success.

- Collaboration between local rural primary health clinic and urban CVT team enhanced the model's effectiveness.

- Initially the team met with the patient/caregiver dyad for intake. Followed by one-on-one patient assessment with each profession. The care team then met to formulate an assessment and care plan which was reviewed by the patient/caregiver dyad to review the plan. - Ongoing communication and decision making occurred concurrently. Follow-up took place among the care team and between the care team and patient-caregiver dyad.

- Intensive and systematic training of new teams by the specialized memory clinic team was deemed as essential. 


\begin{tabular}{|c|c|}
\hline Author, Year, \& Title & Purpose \\
\hline $\begin{array}{l}\text { Morgan et al. (2009) } \\
\text { Improving access to dementia } \\
\text { care: Development and } \\
\text { evaluation of a rural and } \\
\text { remote memory clinic }\end{array}$ & $\begin{array}{l}\text { To describe the development, } \\
\text { implementation and } \\
\text { evaluation of an interdisciplinary } \\
\text { memory clinic aimed at } \\
\text { improving access to diagnosis } \\
\text { and management of early } \\
\text { stage dementia for older } \\
\text { persons living in rural and } \\
\text { remote areas }\end{array}$ \\
\hline
\end{tabular}

\section{Methods, Participants, \& Setting}

Methods: Mixed methods were used to evaluate the acceptability of the interdisciplinary integrated one-day weekly clinic and to compare telehealth vs. regular in-person follow-up care delivery. Participants \& Settings: Older adults with dementia symptoms living in rural and remote areas (at least $100 \mathrm{~km}$ away from a large urban centre) of Saskatchewan, Canada. Interdisciplinary team was located in an urban centre (Saskatoon, Saskatchewan, Canada).
Barton et al. (2011)

Video-telemedicine in a memory disorders clinic:

Evaluation and management of rural elders with cognitive impairment
To describe the implementation of videotelemedicine (VTM) to provide access for rural veterans to a specialty multidisciplinary memory disorders clinic (MDC)
Methods: Mixed methods were used to evaluate the effectiveness of an MDC in simulating an in-person assessment that could be integrated into the regular clinic setting.

Participants \& Setting: All participants were male veterans, with a mean age of 79.1 years (range 71-88 years) who reported living in a rural area. The multidisciplinary team was located in an urban setting (San Francisco, California, USA).
Lee et al. (2017)

Primary care-collaborative clinics: Building capacity for optimized dementia

\section{To describe the need for \\ Methods: Mixed methods were used to evaluation} and implementation of primary care-collaborative memory clinics (PCCMC) the effectiveness of interprofessional primary care memory clinics.

Participants \& Setting: Health care professional from family health teams and community health centres $(n=364)$ attending 15 PCCMC training sessions. The health care professionals were located in both rural and urban areas.
Relevant Findings

- Individual with dementia was referred by family physician in local community.

- The interdisciplinary team met to review the new patients' files. The patient and family members were then interviewed jointly by the team. Each team member then carried out their assessmen individually.

- At the end of the day the team met to collectively determine a possible diagnosis (the referring family physician was invited to oin via telephone). Following this the team met with the patient and family to provide feedback based on the clinical assessments and recommendations for management and care.

- If possible, the team linked the patient with services available in their area.

- Team clinicians prepared individual written reports that were collated and sent to the referring physician, usually within one week of the assessment.

- All clinical and evaluation data was centrally managed to enhance data quality and accessibility, and to facilitate interdisciplinary analyses.

- The VTM model was based on collaboration among a multidisciplinary specialist team and a local rural primary care provider.

- A specialist with expertise in cognitive assessment was identified as key to supporting primary health care providers.

- A dedicated trained primary care physician at the rural site working with the multidisciplinary team members in the urban centre was also deemed essential.

- Patients were referred to the PCCMC by their family physician. Patients attended the PCCMC and were assessed by the interprofessional team.

- The team reviewed assessment results together and devised a care plan. The assessment results and plan were then shared with the patient and family to ensure their support. The referring physician was sent an electronic report detailing the assessment results and recommended care plan.

- Key elements identified as necessary to the success of PCCMCs included: development and review of goal-oriented, patientfocused care plans which consider unique patient preferences; ongoing communication and information sharing; and active coordination among the interprofessional team. 
Table 2: Continued

\begin{tabular}{|c|c|c|c|}
\hline Author, Year, \& Title & Purpose & Methods, Participants, \& Setting & Relevant Findings \\
\hline $\begin{array}{l}\text { Lee, Hillier, Heckman, et al. (2014) } \\
\text { Primary care-based memory } \\
\text { clinics: Expanding capacity } \\
\text { for dementia care }\end{array}$ & $\begin{array}{l}\text { To assess the quality and } \\
\text { management of dementia } \\
\text { within primary care and to } \\
\text { explore patient and caregiver } \\
\text { satisfaction with the memory } \\
\text { clinic and the timeliness of } \\
\text { access to assessment, capacity } \\
\text { building among referring } \\
\text { physicians, and the use of } \\
\text { specialist services }\end{array}$ & $\begin{array}{l}\text { Methods: Mixed methods were used to } \\
\text { evaluate development and implementation } \\
\text { of interdisciplinary memory clinics. } \\
\text { Participants \& Setting: The study included } \\
15 \text { Family Health Teams who established a } \\
\text { family physician-led interdisciplinary memory } \\
\text { clinic. A total of } 582 \text { patients were assessed } \\
\text { by the teams. All of these teams were located } \\
\text { in rural and urban settings throughout Central } \\
\text { and Southwestern Ontario, Canada. The teams } \\
\text { served both rural and urban residents. }\end{array}$ & $\begin{array}{l}\text { - The primary-care memory clinics were led by specially trained } \\
\text { family physicians. } \\
\text { - Geriatricians' conducted chart audits which revealed a high level } \\
\text { of agreement (between geriatricians and trained family physicians) } \\
\text { with diagnosis and management. } \\
\text { - The clinics resulted in timely access to collaborative dementia care; } \\
\text { in turn enhancing service utilization by more-efficient use of geriatric } \\
\text { specialist resources. }\end{array}$ \\
\hline $\begin{array}{l}\text { Lee, Hillier, \& Weston (2014) } \\
\text { Ensuring the success of } \\
\text { interprofessional teams: } \\
\text { Key lessons learned in } \\
\text { memory clinics }\end{array}$ & $\begin{array}{l}\text { To examine the factors that } \\
\text { facilitate and challenge } \\
\text { the development and } \\
\text { implementation of } \\
\text { interdisciplinary } \\
\text { memory clinics }\end{array}$ & $\begin{array}{l}\text { Methods: Qualitative interviews (one-on-one } \\
\text { and focus groups) were employed to gather } \\
\text { information from participants ( } n=31 \text { ). } \\
\text { Participants \& Settings: Included } 13 \text { Family } \\
\text { health team clinics with } 40 \text { clinic members } \\
\text { that had a combined patient base of } 26,000 \text {. } \\
\text { The clinics were located in urban and rural } \\
\text { centres, serving both rural and urban patients } \\
\text { in Central and Southwestern Ontario, Canada. }\end{array}$ & $\begin{array}{l}\text { - Five factors were identified as facilitators to clinic implementation: } \\
\text { (1) memory clinic training program; (2) comprehensive model of } \\
\text { care; (3) availability of human and physical resources; (4) access to } \\
\text { ongoing support; and (5) good communication within clinics. } \\
\text { - For clinics in low resource areas, partnering with the Alzheimer's } \\
\text { Society provided additional expertise and facilitated timely access } \\
\text { to education and support services to patients and families. } \\
\text { - Team building activities were implemented both related to work } \\
\text { (team work on case studies) and informal socialization opportunities } \\
\text { (traveling together, hotel sharing etc.). } \\
\text { - A key element was to start the clinics on a small scale, test processes } \\
\text { and revise according to feedback. }\end{array}$ \\
\hline $\begin{array}{l}\text { Engedal et al. (2012) } \\
\text { Assessment of dementia } \\
\text { by a primary health care } \\
\text { dementia team cooperating } \\
\text { with the family doctor - The } \\
\text { Norwegian model }\end{array}$ & $\begin{array}{l}\text { To evaluate a model for } \\
\text { conducting dementia } \\
\text { assessment with } \\
\text { cooperation between } \\
\text { local authority dementia } \\
\text { nurses and family doctors }\end{array}$ & $\begin{array}{l}\text { Methods: Mixed methods were employed to evaluate } \\
\text { this dementia diagnosis model in two phases. } \\
\text { Participants \& Settings: The study had two } \\
\text { groups of participants (one group per } \\
\text { study phase). In the first phase } 104 \text { patients } \\
\text { came from Oslo, the capital city in Kalmar, } \\
\text { Sweden. The second sample consisted of } \\
\text { patients from small cities and local rural } \\
\text { authorities. Half of these were rural } \\
\text { communities with less than 10,000 inhabitants } \\
\text { (some with less than 2,000). }\end{array}$ & $\begin{array}{l}\text { - All members of the dementia teams in phases one and two received } \\
\text { training in how to use the scales and the procedures for the } \\
\text { assessment. } \\
\text { - When doctors had the support of a specialist they were more } \\
\text { likely to make an etiological diagnosis. } \\
\text { - Even with training, some family doctors reported that the dementia } \\
\text { assessment was time-consuming. } \\
\text { - The domiciliary nurses reported that the dementia team model } \\
\text { was very effective. } \\
\text { - Nurses suggested that the main task for the teams should not be } \\
\text { to do the assessment in cooperation with the family doctors, but to } \\
\text { make a care plan and follow up the patients and the families. }\end{array}$ \\
\hline
\end{tabular}




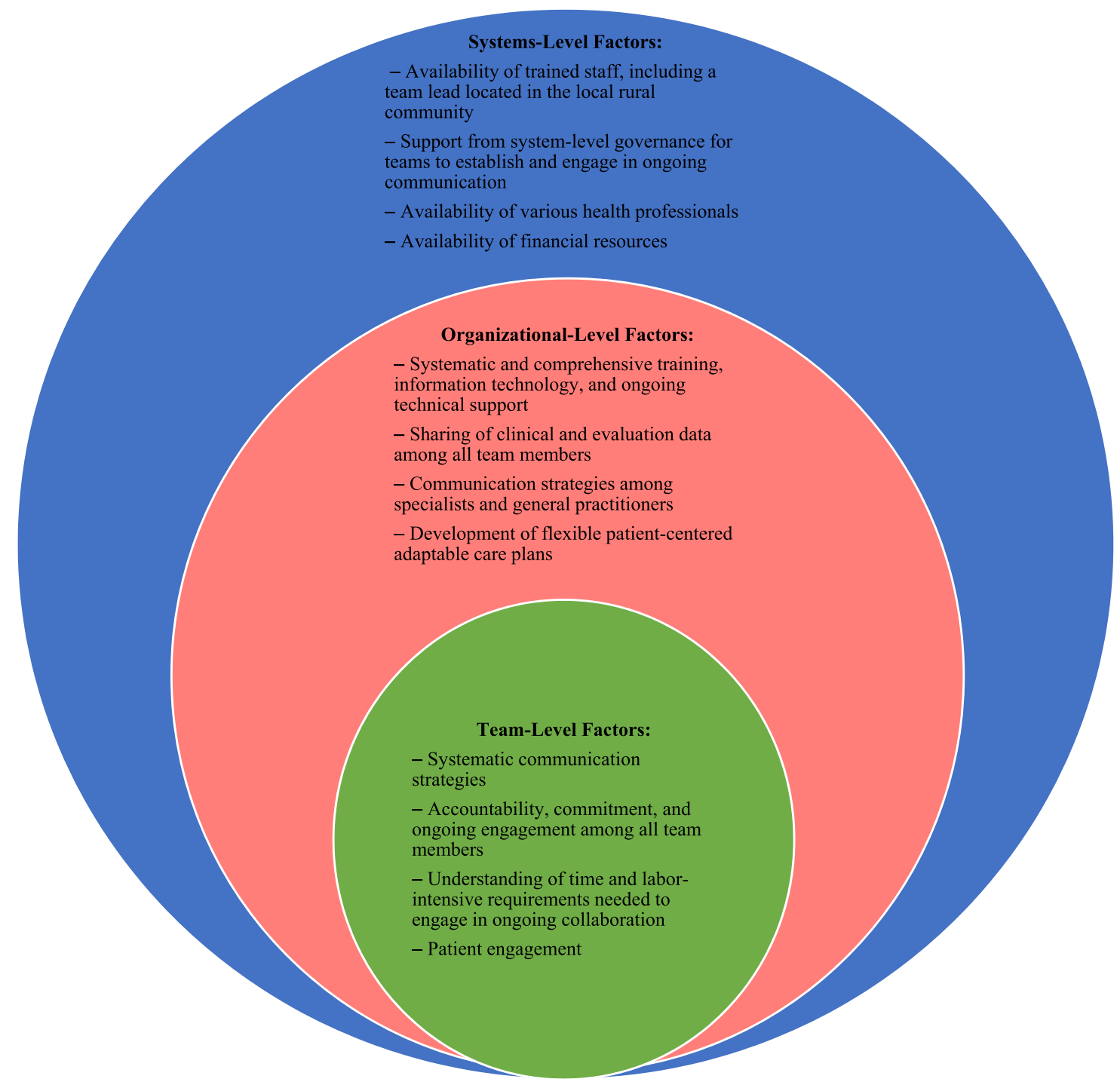

Figure 2: Adapted socio-ecological model depicting factors influencing team-based PHC

\section{Results}

The 10 studies we included span four different countries: Canada (5); United States (3); United Kingdom (1); and Norway (1). Of the five Canadian articles, four reported on the same group of primary care memory clinics within the province of Ontario (Lee, Hillier, Heckman, et al., 2014; Lee, Hillier, Molnar, \& Borrie, 2017; Lee, Hillier, \& Weston, 2014; RojasFernandez, Patel, \& Lee, 2014). The majority (8) of the articles focused on the impact of implementing team-based approaches for dementia diagnosis and treatment to support individuals living in their home or in residential care. The remaining two articles discussed the feasibility of implementing a primary care approach and on how specialist and general practitioners may or may not work together. Among all included studies, a portion of the participants resided in a rural area. However, few details were provided about the rural settings, with only one study providing a definition of rural (Morgan et al., 2009).

The broad goal of this scoping review was to understand how PHC teams collaborate to care for rural and remote residents living with dementia. Overall, eight studies provided some detail on practices that teams engage in when diagnosing and treating dementia among rural residents (Barton, Morris, Rothlind, \& Yaffe, 2011; Engedal, Gausdal, Gjøra, \& Haugen, 2013; Iliffe et al., 2014; Lee et al., 2017; Lee, Hillier, \& Weston, 2014; Morgan et al., 2009; Powers, Homer, Morone, Edmonds, \& Rossi, 2017; RojasFernandez et al., 2014). However, of these eight studies only four included primary health care teams that were located in local rural communities (Engedal et al., 2013; Iliffe et al., 2014; Lee et al., 2017; Lee, Hillier, \& Weston, 2014). 
The secondary goal of this study was to understand how sex and gender was considered in team-based collaboration and delivery of care; unfortunately, the included studies lacked sufficient information to explore sex and gender, with only two studies reporting the sex of patients (Barton et al., 2011; Powers et al., 2017).

The following section addresses results from the scoping review's specific research questions: (a) how do the PHC teams describe themselves; and (b) what factors (facilitators and barriers) are identified which are perceived as promoting or hindering the implementation of collaborative team-based primary health care for those living with dementia in rural and remote areas.

\section{Primary Health Care Teams}

Six studies explained that teams engaged in interdisciplinary/interprofessional collaboration to diagnose and, in some cases, deliver treatment to rural residents with dementia (Lee, Hillier, Heckman, et al., 2014; Lee et al., 2017; Lee, Hillier, \& Weston, 2014; Morgan et al., 2009; Powers et al., 2017; Rojas-Fernandez et al., 2014). Two articles discussed the involvement of memory clinics led by multidisciplinary teams (Barton et al., 2011; Iliffe et al., 2014). The remaining two articles did not identify the type of team; rather, authors referred to collaboration among team members in terms of "shared care" and a "PHC team collaboration" (Engedal et al., 2013; Iliffe, Wilcock, \& Haworth, 2006).

The number and type of health care professionals composing the teams varied among studies, with the number of professions per team as few as three (nurse, family doctor, and occupational therapist) and as many as 12 (nurse, nurse practitioner, pharmacist, social worker, family therapist, dietitian, physician assistant, occupational therapist, part-time respiratory therapist, chiropractor, chiropodist, and health educator). The teams tended to be larger if the team focused on both diagnosis and treatment of dementia (as compared to diagnosis only). Additionally, the composition of PHC teams was apparently influenced by team location (rural vs. urban communities). Teams located in rural communities tended to include fewer professions. A description of team compositions and geographic location of the teams can be found in Table 3 .

\section{Key Factors Necessary for Collaborative Team-Based Care}

A variety of facilitators and barriers were identified as impacting (supporting and hindering) the implementation of collaborative approaches to team-based care for individuals with dementia living rural and remote areas. As we have already discussed, the socioecological model provided a framework for understanding these factors at various levels (team level, organizational level, and systems level). A summary of key factors can be found in Figure 2.

\section{Team-Level Factors}

All articles $(n=10)$ reported on the importance of ongoing communication among team members (Barton et al., 2011; Engedal et al., 2013; Iliffe et al., 2014; Iliffe et al., 2006; Lee, Hillier, Heckman, et al., 2014; Lee et al., 2017; Lee, Hillier, \& Weston, 2014; Morgan et al., 2009; Powers et al., 2017; Rojas-Fernandez et al., 2014). Authors reported that the development of regular communication and follow-up procedures among team members to discuss all patients attending the clinic was a key component of developing effective and systematic communication strategies (Morgan et al., 2009; Rojas-Fernandez et al., 2014). The communication and follow-up pertained both to situations when team members were co-located, and when team members were divided by geographic locale. Some teams implemented bi-weekly meetings (Powers et al., 2017) or follow-up meetings with all team members on the same day as the patient assessment (Morgan et al., 2009).

Four of the 10 studies reported on commitment among health professionals as a key element of implementing collaborative team-based approaches (Barton et al., 2011; Engedal et al., 2013; Iliffe et al., 2014; Iliffe et al., 2006; Lee, Hillier, Heckman, et al., 2014; Lee et al., 2017; Lee, Hillier, \& Weston, 2014; Morgan et al., 2009; Powers et al., 2017; Rojas-Fernandez et al., 2014). Directly related to this was the need for all team members to be accountable for their actions and to fulfill their assigned duties; this in turn enhanced role clarity. Lack of continued engagement among team members was identified as a barrier hindering interprofessional collaborations and thus limiting the success of the team-based primary care model (Lee, Hillier, \& Weston, 2014). Lee et al. (2014) found that, during initial diagnosis and treatment, most team members were engaged and willing to work with other health professionals; however, as time went on it was difficult to engage team members in ongoing communication and treatment activities. This may be due in part to the fact that health care professionals had limited understanding and training about the time and labor-intensive commitments of providing dementia care in a team-based clinic model.

Another element associated with ongoing support was the need for team members to take on leadership roles and to step up as champions within the care team. For example, Lee, Hillier, and Weston (2014) reported that physician champions were a key element to ensuring the successful development and implementation of their interprofessional memory clinics. Lastly, two of the studies discussed the need for health professionals to have confidence in their abilities to diagnose and 
Table 3: Primary health care team description and location

\begin{tabular}{|c|c|c|}
\hline Author & Team Description \& Composition & Geographic Location (Rural or Urban Setting) \\
\hline Lliffe et al. (2014) & $\begin{array}{l}\text { Team Description: Multidisciplinary } \\
\text { Team Composition: Practice nurses and social } \\
\text { workers undertook the case manager role in the rural, } \\
\text { inner-city and urban practices where they worked } \\
\text { with family physician and a social worker }\end{array}$ & $\begin{array}{l}\text { Teams were located in rural }(n=1) \text { and urban } \\
(n=3) \text { practices }\end{array}$ \\
\hline Lliffe et al. (2006) & $\begin{array}{l}\text { Team Description: Shared care } \\
\text { Team Composition: Old age psychiatrist, community } \\
\text { mental health nurse, psychologist, primary care nurse, } \\
\text { and general practitioner }\end{array}$ & $\begin{array}{l}\text { General practitioners and specialists were located } \\
\text { in a combination of inner city }(n=3) \text { and rural } \\
\text { practices }(n=2) \text {. }\end{array}$ \\
\hline Powers et al. (2017) & $\begin{array}{l}\text { Team Description: Interprofessional } \\
\text { Team Composition: Geriatrician, geropsychologist, } \\
\text { geriatric psychiatrist or neurologist, and social worker }\end{array}$ & Team was located in an urban setting. \\
\hline Rojas- Fernandez et al. (2014) & $\begin{array}{l}\text { Team Description: Interdisciplinary } \\
\text { Team Composition: Nurse, nurse practitioner, pharmacist, } \\
\text { social worker, family therapist, dietitian, physician assistant, } \\
\text { occupational therapist, part-time respiratory therapist, } \\
\text { chiropractor, chiropodist, and health educator }\end{array}$ & Team was located in an urban setting. \\
\hline Morgan et al. (2009) & $\begin{array}{l}\text { Team Description: Interdisciplinary } \\
\text { Team Composition: Neurologist, neuropsychology team, } \\
\text { geriatrician, neuroradiologist, nurse, and physical therapist }\end{array}$ & Team was located in an urban setting. \\
\hline Barton et al. (2011) & $\begin{array}{l}\text { Team Description: Multidisciplinary team } \\
\text { Team Composition: Specialist in cognitive assessment, } \\
\text { family physician, other team members not specified }\end{array}$ & Team was located in an urban setting. \\
\hline Lee et al. (2017) & $\begin{array}{l}\text { Team Description: Interprofessional } \\
\text { Team Composition: Trained memory clinic physician, } \\
\text { nurse, social worker, pharmacist, occupational therapist, } \\
\text { Alzheimer's Society representative (if available) }\end{array}$ & Teams were located in urban and rural settings. \\
\hline Lee, Hillier, Heckman, et al. (2014) & $\begin{array}{l}\text { Team Description: Interdisciplinary } \\
\text { Team Composition: At a minimum each memory } \\
\text { clinic had a family physician, nurse, nurse practitioners } \\
\text { and registered practical nurse. Some clinics also had } \\
\text { health professionals from social work, pharmacy, } \\
\text { occupational therapy and mental health counselling }\end{array}$ & Teams were located in urban and rural settings. \\
\hline Lee, Hillier, \& Weston (2014) & $\begin{array}{l}\text { Team Description: Interdisciplinary } \\
\text { Team Composition: Family physician, nurses, social } \\
\text { worker, pharmacist, and occupational therapist }\end{array}$ & Teams were located in urban and rural settings. \\
\hline Engedal et al. (2012) & $\begin{array}{l}\text { Team Description: Primary health care team } \\
\text { Team Composition: Family physician, nurse, } \\
\text { occupational therapist }\end{array}$ & Teams were located in rural and urban settings. \\
\hline
\end{tabular}

treat individuals with dementia. This element seemed to be particularly important when teams were not co-located (i.e., health care staff were required to travel between clinics in a number of surrounding rural communities) (Iliffe et al., 2006; Morgan et al., 2009). For example, some clinicians in local rural clinics were reluctant to test and adapt their skills and to engage in new procedures associated with implementing the team-based approach to dementia care (Engedal et al., 2013).

The ability of teams to engage and interact with patients was indicated in five studies as playing a key role in implementing the team-based approach to dementia care (Lee, Hillier, Heckman, et al., 2014; Lee et al., 2017; Lee, Hillier, \& Weston, 2014; Morgan et al., 2009; RojasFernandez et al., 2014). Ability to engage with patients was closely linked to reluctance of patients to attend the clinic or to complete assessments while at the clinic. Specifically, this was identified as a barrier that teams faced when attempting to engage in ongoing implementation and communication with patients. Reluctance to engage often co-occurred with patients' reservations in bringing a family member to clinic visits (Lee, Hillier, \& Weston, 2014). This reluctance, in turn, often hindered patient engagement because many patients had cognitive challenges and needed assistance in understanding the requests and instructions from the health care professionals. An additional factor impacting the teams' ability to engage patients was the lack of flexibility in developing person-centred adaptable care plans. Such plans are important for effective patient engagement and should include processes which respect patients' preferences, aim to educate the person with 
dementia and their caregivers, and provide necessary physical and emotional support (The Picker Institute, 2013). Tailoring the care plans for patients was shown to be essential in ensuring that the unique needs of patients with dementia living in rural areas could be addressed (Engedal et al., 2013; Iliffe et al., 2014; Morgan et al., 2009).

\section{Organizational-Level Factors}

Access to systematic and comprehensive training for team members was identified as a key element in nine of the included studies (Barton et al., 2011; Engedal et al., 2013; Iliffe et al., 2014; Iliffe et al., 2006; Lee, Hillier, Heckman, et al., 2014; Lee et al., 2017; Lee, Hillier, \& Weston, 2014; Morgan et al., 2009; Rojas-Fernandez et al., 2014). Insufficient training among some primary health care team members made it difficult for the team to work closely and engage in interdisciplinary processes. This was particularly true for professionals who were accustomed to working on their own and had not previously collaborated with other professionals (RojasFernandez et al., 2014). Authors from three studies suggested that important features of the training included offering in-person sessions on multiple occasions. In addition, standardization of documentation and program delivery was important to ensuring that all team members received the same quality of training (Engedal et al., 2013; Iliffe et al., 2014; RojasFernandez et al., 2014).

Access to information technology and ongoing support for these tools was another important organizational factor influencing team-based collaboration; this was particularly true for telehealth clinics (Barton et al., 2011; Engedal et al., 2013). Having access to a reliable internet connection, for example, is necessary for delivery of the telehealth videoconferencing system. However, some rural and remote regions had limited access to internet and the corresponding technological support needed for the telehealth technology. As a result, this could impede communication between team members who were not co-located, thus hindering interprofessional collaboration among teams and, in turn, delivery of care for persons with dementia (Powers et al., 2017). Additionally, two studies stated that clinical and evaluation data should be shared and available (ideally electronically) to all care team members, even when teams were not co-located (Engedal et al., 2013; Morgan et al., 2009).

Access to information was also associated with facilitating another key element, which was communication among specialist teams and the referring family physician in the local community. Six studies noted the importance of implementing communication strategies between the specialist dementia care team members located in the urban centre and the local community-based health care practitioners (e.g., social worker, referring doctor, nurse practitioner) located in the patient's rural community (Barton et al., 2011; Engedal et al., 2013; Lee et al., 2017; Lee, Hillier, \& Weston, 2014; Morgan et al., 2009; Rojas-Fernandez et al., 2014). Such strategies were imperative for ensuring continuity in care between a specialist's recommendations and PHC practices. In some cases, resistance among primary care physicians in rural clinics to engage with care teams located in a larger urban community was a barrier that hindered ongoing interprofessional collaborations (Iliffe et al., 2006; Morgan et al., 2009). Lack of communication between the specialist team and the local physician also made it difficult to implement patient-focused care plans.

\section{Systems-Level Factors}

All articles noted that the availability of trained staff was essential to the success of implementing interprofessional team-based care models (Barton et al., 2011; Engedal et al., 2013; Iliffe et al., 2014; Iliffe et al., 2006; Lee, Hillier, Heckman, et al., 2014; Lee et al., 2017; Lee, Hillier, \& Weston, 2014; Morgan et al., 2009; Powers et al., 2017; Rojas-Fernandez et al., 2014;). In models where there was collaboration between an urbanbased care team and rural health care professionals, a dedicated and trained family physician or nurse practitioner acting as team lead was shown to be an asset in the local rural clinic. Another factor associated with staff availability was the turnover of team members. This was particularly challenging if mechanisms and resources were not available to ensure that incoming staff received the required training (Lee, Hillier, \& Weston, 2014).

Support from system-level governance for team members to have dedicated time to establish and engage in ongoing communication processes was important. Lack of time and support for health care staff to engage in ongoing collaboration and planning as a team was noted as a barrier in three of the included studies (Engedal et al., 2013; Iliffe et al., 2006; Powers et al., 2017). Adding to this challenge was the fact that rural communities often had access to fewer disciplines, and thus team members were required to take on a number of additional duties. In turn, this limited the time staff could devote to ongoing collaborations with the team.

We identified the availability of financial resources to support ongoing implementation of team-based approaches as a necessary element contributing to both human resources and infrastructure (space for teams to work collaboratively and, in some cases, assess patients) in all of the studies (Barton et al., 2011; Engedal et al., 2013; Iliffe et al., 2014; Iliffe et al., 2006; Lee, Hillier, Heckman, et al., 2014; Lee et al., 2017; Lee, Hillier, \& Weston, 2014; Morgan et al., 2009; Powers et al., 2017; 
Rojas-Fernandez et al., 2014). Thus, if funds were not available, the teams could not always hire the necessary staff to support the implementation of the collaborative team-based care model. Moreover, when infrastructure was limited, financial resources were required to expand or upgrade spaces to accommodate teams.

\section{Discussion}

In this study we aimed to understand how PHC teams collaborate to deliver comprehensive and integrated dementia care in rural and remote areas. In a previous scoping review, Dahlke et al. (2017) investigated how interprofessional teams collaborated to care for older adults with cognitive challenges; however, they did not focus on delivering team-based care in rural and remote areas. Given the unique contextual factors associated with living in rural settings and the fact that many older adults reside in those areas (Morgan et al., 2015; Prince et al., 2016), our scoping review has addressed an important area of research. Overall, the 10 articles we examined provided information on both types of PHC teams with variation in team composition. In addition, we sought to explore factors influencing how PHC providers engage in team-based collaboration when caring for rural residents living with dementia. A secondary goal of the current study was to examine sex and gender differences in relation to needs and care approaches for patients and families, and also to study how PHC teams function to deliver care to rural and remote areas for residents living with dementia; however, due to the limited information pertaining to sex and gender in the 10 studies identified, we were unable to address this question in our scoping review.

Understanding the context and environment associated with rural and remote settings was pertinent to addressing the primary aim of this scoping review. All studies included participants from rural and remote areas, but only one study in our review provided a definition describing the rural setting (Morgan et al., 2009). Given the unique contextual factors associated with living in rural and remote communities, it is important that readers understand how rural is defined within each study. Further, because there is no universally agreed-upon definition of rural, it was difficult to determine the degree of rurality (e.g., how distant the communities were from an urban centre) and the differing contextual and environmental factors impacting the implementation of team-based care approaches in each study.

Another issue associated with the broader aim of understanding how PHC teams collaborate was that few studies implemented team-based approaches via a local PHC team working in the same community as did the rural residents. In a number of the studies, the collaborative team-based approach included a specialist team located in an urban setting. Although the expertise of these specialists is important, research suggests that in low-resource settings (such as rural areas), primary health care should play a key role in delivering care to those living with dementia (Prince et al., 2016). Thus, rather than referring all individuals who report dementia symptoms to specialist teams, capacity should be built for local PHC teams (trained and supported by specialists) to play a leadership role in coordinating the diagnosis and treatment for those living with dementia in rural and remote areas (Aminzadeh et al., 2012; Morgan et al., 2015; Prince et al., 2016; Wakerman, 2009). For more complex cases, where determining diagnosis and treatment is difficult, the PHC team could then refer the patients to a specialist team (Hum et al., 2014; Morgan et al., 2009). Four of the five Canadian studies discussed the implementation of PHC teams, and the authors reported successes in building capacity among PHC teams with corresponding increases in patient satisfaction; it should be noted that the four studies reporting successes were based on the same primary care-based memory clinic model (Lee, Hillier, Heckman, et al., 2014; Lee et al., 2017; Lee, Hillier, \& Weston, 2014; Rojas-Fernandez et al., 2014).

In addition to our broad research aim of understanding how PHC teams work collaboratively to care for individuals living with dementia in rural and remote areas, we attempted to address two specific research questions. Our first research question was to determine if and how primary health care teams describe the team-based approach they employed; and to identify the various team compositions. All studies reported working as a particular type of team (interdisciplinary/interprofessional, multidisciplinary, shared care, and primary health care); however, few studies included a specific definition for the type of team employed. Consequently, the corresponding definition with the team type identified did not always match the process by which the teams did or did not collaborate. For example, one study referred to implementing a multidisciplinary teambased approach when in fact their team was working collaboratively with multiple health professionals and could have been more accurately described as an interdisciplinary/interprofessional team (Iliffe et al., 2014). This finding supports previous recommendations for the need to establish consistency in terminology used to describe and differentiate how various types of health care teams function (Chamberlain-Salaun et al., 2013). Establishing consensus in terminology and associated definitions will, in turn, provide a better understanding of the division of roles and benefits of interdisciplinary / interprofessional collaborations when caring for those with dementia in primary care settings. 
When investigating the various team compositions, we found that most authors identified the health professionals included on their teams; for example, all teams included a specialist or general practitioner and a nurse. Additional team members varied across studies and within studies that had multiple teams. The availability of multiple professions tended to be limited when PHC teams were located in rural communities (i.e., rural-based teams had more limited access to a variety of health care professionals). This finding provides further support for the recommendation that PHC teams in rural communities should be supported in order to provide more comprehensive and integrated dementia care (Boscart, 2016).

Our second research question was to identify factors that teams perceived as influencing the implementation of collaborative team-based approaches when caring for rural residents living with dementia. We employed an adapted version of the socio-ecological model to understand and organize these key factors by team level, organizational level, and systems level. At the team level, the most commonly reported factor was ongoing communication among the care team. This included establishing mechanisms to ensure that teams met on a regular basis to discuss the diagnosis and treatment plans for patients. The need for regular communication was also identified by Dahlke et al. (2017) as key to supporting interprofessional collaborations among care teams. An issue related to communication among team members, but unique to rural settings, was how specialist teams and the referring family physician interacted. In some cases, the family physician was reluctant to engage with the specialist team (Iliffe et al., 2006; Morgan et al., 2009). However, Lee et al. (2014) demonstrated that when the primary care physicians engaged in ongoing communication and received support from specialists, they were more confident and efficient in diagnosing and treating patients with local supports and resources. This approach is supported by the World Alzheimer Report 2016 (Prince et al., 2016), which identified the need for low-resource rural areas to build capacity through training of primary care staff and to connect patients with local services. Moreover, engaging the family physician directly thereby links to the most common factor identified at the organizational level, which was access to systematic and comprehensive training and education for all team members.

Similar findings have been reported in studies employing telehealth approaches to diagnosing and treating dementia among rural residents. For instance, the training of local health professionals in rural communities was deemed essential to ensure that telehealth tools are implemented effectively (Barth et al., 2018). In addition, training to increase education and knowledge among local primary care teams was linked to increases in patient satisfaction (Barton et al., 2011; Lee, Hillier, Heckman, et al., 2014; Lee, Hillier, \& Weston, 2014).

At the systems level, the most commonly identified factors included human and financial resources to support ongoing collaborations among care teams. These findings were similar to those reported by Dahlke et al. (2017) wherein low staffing levels were identified as a barrier to ongoing implementation of collaborative team-based approaches to care. A factor related to human and financial resources was that rural and remote communities often lacked the population base to support hiring a wide range of health care professionals and specialists. Adding to this challenge was the high rate of staff turnover, particularly among primary care physicians in rural communities (McGrail, Wingrove, Petterson, \& Bazemore, 2017; Pong \& Pitblado, 2005). High turnover resulted in added burden on primary health care team members, particularly when they were required to take on additional roles for which they did not have sufficient training and education.

The combined findings and literature gaps identified in this scoping review have research, practice, and policy implications.

\section{Recommendations for Research}

Future research should focus on reporting the specific definition of rural employed in the study; in addition, a detailed description of the rural setting in which the study was conducted should be provided. The provision of such contextual information will assist the reader in determining if the reported findings are transferable to other rural environments.

A second recommendation for future research is the step-by-step documentation of specific processes that local interprofessional PHC teams engage in when they are diagnosing and delivering treatment to rural and remote residents living with dementia. This includes developing an understanding of how specialists in urban areas and PHC professionals in rural settings collaborate in task sharing, with the goal of supporting primary care teams to build capacity and take on a leadership role in the diagnosis and treatment of dementia (Prince et al., 2016). Combined, this information will inform the development of a dementia primary care model, which incorporates best practices specifically tailored to the unique needs of rural and remote residents being cared for in their local community. Finally, future research in this area should include a focus on identifying and exploring sex and gender differences that influence how PHC teams collaborate to support rural residents living with dementia. 


\section{Recommendations for Practice}

When health care professionals engage in team-based care, it is important that they take time to define and understand the type of team they are attempting to establish (e.g., interdisciplinary/interprofessional vs. multidisciplinary/multiprofessional). From the outset, these teams should identify a common purpose, performance goals, and mechanisms for facilitating communication and collaboration. This includes establishing a team lead and identifying team roles and responsibilities. Developing such protocols will support rural PHC teams in building capacity and becoming more proficient in diagnosing and treating dementia. In addition, rural-based PHC teams, which are often not co-located, need to have additional mechanisms in place to aid in relationship building and promote both formal and informal interactions. Further, rural PHC teams should work collaboratively with specialist teams (typically located in urban areas) to develop skills in diagnosis and treatment of persons with dementia. Moreover, a mechanism should be in place to support PHC teams in referring more complex cases to a specialist team. In turn, this would increase the availability of specialist services for more complex dementia cases.

\section{Recommendations for Policy}

The findings of this scoping review may be used to inform policy development, particularly among local rural health authorities. Specifically, local governance should develop guidelines for facilitating collaboration among multiple health care professionals while simultaneously addressing system-level barriers identified by team members. In addition, health authorities should be responsible for ensuring that resources are in place to provide all necessary training for all team members, including additional supports for those in team leadership roles. Finally, local governance should establish protocols for prioritizing patient engagement during the development and implementation of any rural PHC model for dementia care. Ensuring a person-centred approach is at the core of all rural PHC teams caring for persons with dementia.

\section{Limitations}

Limitations identified in this study include the elimination of grey literature which potentially contained relevant information; as a result, literature beneficial to this scoping review may have been missed. A second limitation is that our review included only Englishlanguage publications. A further limitation is that given the nature of the scoping review process, included articles were not assessed for quality and rigor. All included studies, however, were published in peer-reviewed journals; furthermore, each article was assessed by two reviewers to ensure that the reported content was relevant to the scoping review aim and objectives. Finally, due to the lack of information about sex and gender among the articles included in this scoping review, we were unable to address and explore sex and gender differences as they related to both delivery of care and how PHC functions in delivering that care.

\section{Conclusion}

Overall, this scoping review has contributed to a better understanding of the diverse team compositions that are employed to diagnose and treat dementia in rural and remote settings. Key factors (barriers and facilitators) shown to influence how teams collaborate to deliver dementia care to rural and remote residents were identified. Moreover, four of the included articles detailed the specific processes local PHC teams employed to deliver collaborative and comprehensive dementia care to residents living in rural and remote areas. Moving forward, we plan to engage with rural PHC teams to further understand how teams are implementing collaborative care approaches for rural residents living with dementia and other chronic conditions. In addition, the findings from this review are being used to inform the development of a rural and remote PHC dementia model. Specifically, applicable processes identified in the current scoping review will be incorporated into the model and evaluated for their effectiveness in supporting teambased PHC for rural residents living with dementia. Combined, this will result in a PHC model consisting of evidence-based best practices for rural dementia care.

\section{References}

Alzheimer Society of Canada. (2016). Prevalence and monetary costs of dementia in Canada (2016): A report by the Alzheimer Society of Canada. Health Promotion and Chronic Disease Prevention in Canada, 36(10), 231-232. https:// www.ncbi.nlm.nih.gov/pmc/articles/PMC5158126/ pdf/36_10_4.pdf

Aminzadeh, F., Molnar, F. J., Dalziel, W. B., \& Ayotte, D. (2012). A review of barriers and enablers to diagnosis and management of persons with dementia in primary care. Canadian Geriatrics Journal: CGJ, 15(3), 85-94. https://doi.org/10.5770/cgj.15.42

Arksey, H., \& O'Malley, L. (2005). Scoping studies: Towards a methodological framework. International Journal of Social Research Methodology: Theory and Practice, 8(1), 19-32. https://doi.org/10.1080/1364557032000119616

Barth, J., Nickel, F., \& Kolominsky-Rabas, P. L. (2018). Diagnosis of cognitive decline and dementia in rural areasA scoping review. Geriatric Psychiatry, 33(3), 459-474. Retrieved from https://doi.org/10.1002/gps.4841

Barton, C., Morris, R., Rothlind, J., \& Yaffe, K. (2011). Videotelemedicine in a memory disorders clinic: Evaluation 
and management of rural elders with cognitive impairment. Telemedicine and E-Health, 17(10), 789-793. https: / / doi.org/10.1089/tmj.2011.0083

Boscart, V. (2016). Dementia in Canada. (2016). Retrieved from http://rnao.ca/sites/rnao-ca/files/Joint_Submission_re_ Dementia_CGNA_and_RNAO-_Apr_6_2016_-_FINAL_1. pdf

Bradford, A., Kunik, M. E., Schulz, P., Williams, S. P., \& Singh, H. (2009). Missed and delayed diagnosis of dementia in primary care prevalence and contributing factors. Alzheimer Disease E Associated Disorders, 23(4), 306-314.

Canadian Institutes of Health Research. (2014). Community-based primary health care. Ottawa, ON: Government of Canada. Retrieved from http:/ /www.cihr-irsc.gc.ca/e/43626.html

Chamberlain-Salaun, J., Mills, J., \& Usher, K. (2013). Terminology used to describe health care teams: An integrative review of the literature. Journal of Multidisciplinary Healthcare, 6, 65-74. https: / / doi.org/10.2147/JMDH.S40676

Chertkow, H., Feldman, H. H., Jacova, C., \& Massoud, F. (2013). Definitions of dementia and predementia states in Alzheimer's disease and vascular cognitive impairment: Consensus from the Canadian conference on diagnosis of dementia, 5(Suppl 1), 1-8.

Dahlke, S., Meherali, S., Chambers, T., Freund-Heritage, R., Steil, K., \& Wagg, A. (2017). The care of older adults experiencing cognitive challenges: How interprofessional teams collaborate. Canadian Journal on Aging, 36(4), 1-16.

Dandy, K., \& Bollman, R. D. (2008). Seniors in Rural Canada. Rural and Small Town Canada Analysis Bulletin, 7(8), 1-57.

Engedal, K., Gausdal, M., Gjøra, L., \& Haugen, P. K. (2013). Assessment of dementia by a primary health care dementia team cooperating with the family doctorThe Norwegian model. Dementia and Geriatric Cognitive Disorders, 34(5-6), 263-270. https://doi.org/10.1159/ 000345435

Ford, D. M. (2016). Four persistent rural healthcare challenges. Healthcare Management Forum, 29(6), 243-246. https:/ / doi.org/10.1177/0840470416658903

Goldman, J., Meuser, J., Rogers, J., Lawrie, L., \& Reeves, S. (2010). Interprofessional collaboration in family health teams: An Ontario-based study. Canadian Family Physician, 56(10), e368-e374.

Hum, S., Cohen, C., Persaud, M., Lee, J., Drummond, N., Dalziel, W., \& Pimlott, N. (2014). Role expectations in dementia care among family physicians and specialists. Canadian Geriatrics Journal: CGJ, 17(3), 95-102. https:// doi.org/10.5770/cgj.17.110

Iliffe, S., Robinson, L., Bamford, C., Waugh, A., Fox, C., Livingston, G., ... Katona, C. (2014). Introducing case management for people with dementia in primary care: A mixed-methods study. British Journal of General Practice, 64(628), e735-e741. https: / / doi.org/10.3399/ bjgp14X682333
Iliffe, S., Wilcock, J., \& Haworth, D. (2006). Obstacles to shared care for patients with dementia: A qualitative study. Family Practice, 23(3), 353-362. https://doi.org/10.1093/ fampra/cmi116

Innes, A., Morgan, D., \& Kostineuk, J. (2011). Dementia care in rural and remote settings: A systematic review of informal/family caregiving. Maturitas, 68(1), 34-46. https://doi.org/10.1016/j.maturitas.2010.10.002

Keating, N., Swindle, J., \& Fletcher, S. (2011). Aging in rural Canada: A retrospective and review. Canadian Journal on Aging, 30(3), 323-338. https://doi.org/ $10.1017 /$ S0714980811000250

Lee, L., Hillier, L. M., Heckman, G., Gagnon, M., Borrie, M. J., Stolee, P., \& Harvey, D. (2014). Primary care-based memory clinics: Expanding capacity for dementia care. Canadian Journal on Aging, 33(3), 307-319. https:/ /doi.org/10.1017/ S0714980814000233

Lee, L., Hillier, L. M., Molnar, F., \& Borrie, M. J. (2017). Primary care collaborative memory clinics: Building capacity for optimized dementia care. Healthcare Quarterly, 19(4), 55-62. Retrieved from http://cyber. usask.ca/login?url=http:/ / search.ebscohost.com / login.aspx?direct $=$ true $\& \mathrm{db}=\mathrm{rzh} \& \mathrm{AN}=123294729 \&$ site $=$ ehost-live

Lee, L., Hillier, L. M., \& Weston, W. W. (2014). Ensuring the success of interprofessional teams: Key lessons learned in memory clinics. Canadian Journal on Aging, 33(1), 49-59. https:/ / doi.org/10.1017/S0714980813000652

Levac, D., Colquhoun, H., \& O’Brien, K. K. (2010). Scoping studies: Advancing the methodology. Implementation Science, 5(1), 1-9. https:/ / doi.org/10.1186/1748-5908-5-69

Massoud, F., Lysy, P., \& Bergman, H. (2010). Care of dementia in Canada: A collaborative care approach with a central role for the primary care physician. The Journal of Nutrition, Health E Aging, 14(2), 105-106. https: / / doi.org/10.1007/ s12603-010-0020-2

McGrail, M. R., Wingrove, P. M., Petterson, S. M., \& Bazemore, A. W. (2017). Mobility of US rural primary care physicians during 2000-2014. The Annals of Family Medicine, 15(4), 322-328. https:/ / doi.org/10.1370/ afm.2096

McLeroy, K. R., Bibeau, D., Steckler, A., \& Glanz, K. (1988). An ecological perspective on health promotion programs. Health Education \& Behavior, 15(4), 351-377. https:// doi.org/10.1177/109019818801500401

Mickan, S. M., \& Rodger, S. A. (2005). Effective health care teams: A model of six characteristics developed from shared perceptions. Journal of Interprofessional Care, 19(4), 358-370. https:/ / doi.org/10.1080/13561820500165142

Misfeldt, R., Suter, E., Oelke, N., \& Hepp, S. (2017). Creating high performing primary health care teams in Alberta, Canada: Mapping out the key issues using a socioecological model. Journal of Interprofessional Education and Practice, 6, 27-32. https:/ / doi.org/10.1016/j.xjep.2016.11.004 
Moazzami, B. (2015). Strengthening rural Canada: Fewer $\mathcal{E}$ older: Population and demographic challenges across rural Canada. A Pan-Canadian report. Ottawa, ON: Government of Canada. Retrieved from http: / / www. essentialskillsontario.ca/sites/www.essentialskillsontario. ca/files/Fewer \& Older - Population and Demographic Challenges Across Rural Canada.pdf

Morgan, D. G., Crossley, M., Kirk, A., D'Arcy, C., Stewart, N., Biem, J., ... McBain, L. (2009). Improving access to dementia care: Development and evaluation of a rural and remote memory clinic. Aging and Mental Health, 13(1), 17-30. https:/ / doi.org/10.1080/13607860802154432

Morgan, D. G., Kosteniuk, J. G., Stewart, N. J., O'Connell, M. E., Kirk, A., Crossley, M., ... Innes, A. (2015). Availability and primary health care orientation of dementia-related services in rural Saskatchewan, Canada. Home Health Care Services Quarterly, 34(3-4), 137-158. https: / / doi.org /10.1080/01621424.2015.1092907

Mulvale, G., Danner, U., \& Pasic, D. (2008). Advancing community-based collaborative mental health care through interdisciplinary family health teams in Ontario. Canadian Journal of Community Mental Health, 27(2), 55-73. https: / / doi.org/10.7870/cjcmh-2008-0018

Pong, R. W., \& Pitblado, J. R. (2005). Geographic distribution of physicians in Canada: Beyond how many and where, Vol. 11. Ottawa, ON: Canadian Institute for Health Information. Retrieved from https: / / secure.cihi.ca/free_products / Geographic_Distribution_of_Physicians_FINAL_e.pdf

Powers, B. B., Homer, M. C., Morone, N., Edmonds, N., \& Rossi, M. I. (2017). Creation of an interprofessional teledementia clinic for rural veterans: Preliminary data. Journal of the American Geriatrics Society, 65(5), 1092-1099. https:/ /doi.org/10.1111/jgs.14839

Prince, M., Albanese, E., Guerchet, M., \& Prina, M. (2014). World Alzheimer Report 2014. Dementia and risk reduction: An analysis of protective and modifiable factors. London, ENG: Alzheimer's Disease International. Retrieved from https://www.alz.co.uk/research/ WorldAlzheimerReport2014.pdf

Prince, M., Comas-Herrera, A., Knapp, M., Guerchet, M., \& Karagiannidou, M. (2016). World Alzheimer Report 2016 Improving healthcare for people living with dementia:
Coverage, quality and costs now and in the future. London, ENG: Alzheimer's Disease International. Retrieved from https://www.alz.co.uk/research/ WorldAlzheimerReport2016.pdf

Reeves, S., Goldman, J., Gilbert, J., Tepper, J., Silver, I., Suter, E., \& Zwarenstein, M. (2011). A scoping review to improve conceptual clarity of interprofessional interventions. Journal of Interprofessional Care, 25(3), 167-174. https: / / doi.org/10.3109/13561820.2010.529960

Reeves, S., McMillan, S. E., Kachan, N., Paradis, E., Leslie, M., \& Kitto, S. (2015). Interprofessional collaboration and family member involvement in intensive care units: Emerging themes from a multi-sited ethnography. Journal of Interprofessional Care, 29(3), 230-237. https:/ / doi.org/10.3109/13561820.2014.955914

Rojas-Fernandez, C. H., Patel, T., \& Lee, L. (2014). An interdisciplinary memory clinic: Anovel practice setting for pharmacists in primary care. Annals of Pharmacotherapy, 48(6), 785-795. https:/ /doi.org/10.1177/1060028014526857

Russ, T. C., Batty, G. D., Hearnshaw, G. F., Fenton, C., \& Starr, J. M. (2012). Geographical variation in dementia: Systematic review with meta-analysis. International Journal of Epidemiology, 41(4), 1012-1032. https:/ / doi. org/10.1093/ije/dys103

Statistics Canada. (2016). Population by broad age groups and sex, for both sexes, Canada, by Statistical Area Classification, 2016 Census. Retrieved from https://www12.statcan. gc.ca/census-recensement/2016/dp-pd/hlt-fst/as / Table.cfm?Lang=E\&T=21

The Picker Institute. (2013). Patient-centered care: The road ahead. http: / /ipfcc.org/resources / Patient-Centered-CareThe-Road-Ahead.pdf

Tierney, M. C., Curtis, A. F., Chertkow, H., \& Rylett, R. J. (2017). Integrating sex and gender into neurodegeneration research: A six-component strategy. Alzheimer's and Dementia: Translational Research and Clinical Interventions, 3(4), 660-667. https:/ /doi.org/10.1016/j.trci.2017.10.006

Wakerman, J. (2009). Innovative rural and remote primary health care models: What do we know and what are the research priorities? Australian Journal of Rural Health, 17(1), 21-26. https:/ / doi.org/10.1111/j.1440-1584.2008.01032.x 